\title{
Simultaneous Determination of Antimalarial Agents by LC-MS/MS and Its Application to Evaluation of Fixed-Dose Tablets
}

\author{
Breno M. Marson, Raquel O. Vilhena, Flavia L. D. Pontes, Mário S. Piantavini and \\ Roberto Pontarolo*
}

Departamento de Farmácia, Universidade Federal do Paraná, 81531-990 Curitiba-PR, Brazil

\begin{abstract}
We developed and validated a liquid chromatography tandem mass spectrometry (LC-MS/MS) method to quantify the antimalarials artesunate (ARS) and mefloquine (MFQ) in fixed-dose tablets. The detection was performed by a triple-quadrupole mass spectrometer in multiple reaction monitoring (MRM) in positive ion mode via electrospray ionization. Chromatographic separation was achieved with an XBridge $\mathrm{C} 18$ column $(50 \times 2.1 \mathrm{~mm}, 5 \mu \mathrm{m})$, using isocratic elution $\left(350 \mu \mathrm{L} \mathrm{min}^{-1}\right)$ of water/acetonitrile/methanol (30:35:35, v/v/v) containing $0.1 \%$ formic acid. The method was validated according to the International Conference of Harmonization (ICH) guidelines. The calibration curves obtained for ARS (400 to $600 \mathrm{ng} \mathrm{mL}^{-1}$ ) and MFQ (800 to $1200 \mathrm{ng} \mathrm{mL}^{-1}$ ) showed good linearity $\left(\mathrm{r}^{2}>0.99\right)$, precision (relative standard deviation (RSD): ARS $<2.0 \%$; MFQ $<1.9 \%$ ), and accuracy (recoveries: ARS, 102.4-103.4\%; MFQ, 97.4-101.6\%), and were stable for $24 \mathrm{~h}$ at $8{ }^{\circ} \mathrm{C}$. The method was successfully applied to commercial tablets, and recoveries of $98.7 \pm 4.7 \%$ (ARS) and $105.6 \pm 3.13 \%$ (MFQ). The method developed is a reliable alternative for public quality inspection control with the advantage of tandem mass specificity and speed.
\end{abstract}

Keywords: antimalarial, artesunate, LC-MS/MS, mefloquine, validation

\section{Introduction}

Malaria is an infectious disease caused by protozoan parasites of the genus Plasmodium. ${ }^{1}$ Several Plasmodium species are known to infect humans, and Plasmodium falciparum is considered the most dangerous species, since it is responsible for the most severe and fatal cases of malaria. ${ }^{2}$ Malaria is one of the most serious public health concerns worldwide and 3.2 billion people remain at risk of being infected. In 2015, 214 million new cases of malaria and 438,000 deaths were reported. ${ }^{2}$

The treatment of malaria is based on targeting the lifecycle of the parasite. The World Health Organization (WHO) recommends artemisinin-based combination therapies (ACTs), such as artesunate (ARS) $\left(\mathrm{C}_{19} \mathrm{H}_{28} \mathrm{O}_{8}\right.$; $384.42082 \mathrm{~g} \mathrm{~mol}^{-1}$ ) and mefloquine hydrochloride (MFQ) $\left(\mathrm{C}_{17} \mathrm{H}_{16} \mathrm{ClF}_{6} \mathrm{~N}_{2} \mathrm{O} ; 414.77309 \mathrm{~g} \mathrm{~mol}^{-1}\right.$ ) (Figure 1), for the treatment of uncomplicated malaria, caused by $P$. falciparum. ${ }^{2,3}$

ACTs combine two active drugs with different mechanisms of action in order to increase the spectrum of activity and effectiveness, and to prevent antimalarial

*e-mail: pontarolo@ufpr.br drug resistance. In an ACT, the immediate effect of an artemisinin derivative, which rapidly clears asexual blood-stage parasites and gametocytes, is combined with<smiles>C[C@H]1CC[C@H]2[C@@H](C)[C@H](OC(=O)CCC(=O)O)O[C@H]3O[C@]4(C)CC[C@@H]1[C@]32OO4</smiles><smiles>O[C@H](c1cc(C(F)(F)F)nc2c(C(F)(F)F)cccc12)[C@H]1CCCCN1</smiles>

(b)<smiles>COc1ccc2c(c1)c(CC(=O)O)c(C)n2C(=O)c1ccc(Cl)cc1</smiles>

Figure 1. Chemical structures of (a) artesunate; (b) mefloquine; and (c) the internal standard indometacin. 
a drug of a different class that has a longer half-life, thus eliminating residual parasites. ${ }^{4,5}$

One of the barriers in the fight against malaria is the increasing presence on the market of counterfeit drugs, which, in recent years, has led to the development of $P$. falciparum resistance to therapy. ${ }^{6}$ Antimalarials are among the most widely administered drugs in tropical countries and have been particularly targeted by counterfeiters. The use of counterfeit drugs or substandard antimalarial drugs can cause increased morbidity, adverse effects, and mortality owing to excessive dose or presence of potentially toxic ingredients or pathogenic contaminants. Furthermore, counterfeits may contain sub-therapeutic amounts of active ingredients, which would favor the selection of resistant parasites, and thus, resistance to current antimalarial drugs. ${ }^{7}$ Hence, reliable alternatives for public quality inspection control of antimalarial drugs may help to ensure treatment efficacy and avoid the development of resistance to antimalarial drugs. ${ }^{8}$

The design of analytical methods for quality control of pharmaceutical products should be an important research objective to ensure public health improvement. Despite the frequent use of fixed-dose combination tablets of ARS and MFQ, no method for their quality control has been described in the pharmacopoeias. ${ }^{9-12} \mathrm{Few}$ methods for the simultaneous quantification of drugs in pharmaceutical formulations have been published and include UV spectrophotometry, ${ }^{13,14}$ high-performance liquid chromatography (HPLC) with UV spectrophotometry detection, ${ }^{15,16}$ and high-performance thin layer chromatography (HPTLC) with UV spectrophotometry detection. ${ }^{16,17}$

UV spectrophotometry is a simple and cost-effective analytical method; however, the presence of complex mixtures limits its use owing to the low specificity of the technique. ARS has UV maximum absorption at the beginning of the UV spectrum (200-220 nm), because of the absence of chromophores in its structure. ${ }^{15}$ In that particular UV region, other formulation components such as preservatives and color coatings may have absorption, limiting its application to simple and specific mixtures. Additionally, counterfeit drugs may contain other chemicals not expected in the formulation.

Liquid chromatography-diode array detector (LC-DAD) methods have more advantages than UV spectrophotometry methods mainly because of the chromatographic separation of the mixture components. However, in some cases, the presence of impurities limits the chromatographic separation, making the method non-selective. It is important to note that the recommended fixed-dose ACTs contain $25+55 \mathrm{mg}$ (pediatric) or $100+220 \mathrm{mg}$ (adult) of ARS and MFQ, respectively. ${ }^{3}$ Considering this ratio concentration and that MFQ has higher UV absorption than ARS, the UV signal absorption difference between MFQ and ARS can be substantial (up to 40 times). Therefore, in order to achieve good signal intensity for ARS, the MFQ signal intensity used can reach values near the upper limit of detection. ${ }^{18}$

Compared to the techniques described above, the use of liquid chromatography tandem mass spectrometry (LC-MS/MS) presents many advantages. The selectivity of tandem mass spectrometry is higher than that of UV detection even with the use of LC, and it is therefore more adequate for quality inspection control. To the best of our knowledge, no LC-MS/MS method for simultaneous determination of these drugs has been reported. Thus, the aim of the present study was to develop and validate a rapid and selective LC-MS/MS method for direct simultaneous determination of ARS and MFQ in antimalarial tablet formulations.

\section{Experimental}

\section{Standards, chemicals reagents, and samples}

The ARS standard (98.8\%) was purchased from the Brazilian Pharmacopoeia (Brasília, DF, Brazil), the MFQ-hydrochloride standard (98.0\%) was purchased from Sigma-Aldrich (St. Louis, MO, USA), and the internal standard (IS) indomethacin (99.4\%) was purchased from Cspc Ouyi Pharma Co. Ltd. (Shijiazhuang, Hebei, China). HPLC-grade acetonitrile and methanol were purchased from Tedia (Fairfield, USA). Formic acid (99.0\%) was purchased from Carlo Erba Reagenti (Rodano, Italy). Ammonium formate $(97.0 \%$ ) was purchased from Acros Organics (Fair Lawn, NJ, USA). Ultrapure water was obtained in-house by using a Milli-Q purification system from Millipore (Bedford, MA, USA). Fixed-dose combination tablets of ARS-MFQ were provided by Farmanguinhos/Fundação Oswaldo Cruz (Rio de Janeiro, RJ, Brazil) and contained $100 \mathrm{mg}$ of ARS and $220 \mathrm{mg}$ of MFQ (corresponding to $200 \mathrm{mg}$ of MFQ base) per tablet. The quantitative compositions of the excipients were not publicly available.

\section{Stock and working standard solutions}

Stock solutions ( $\left.1 \mathrm{mg} \mathrm{mL}^{-1}\right)$ of ARS, MFQ, and IS were prepared by dissolving accurately weighed reference substances (with an analytical balance, accurate to $\pm 0.0001 \mathrm{~g}$ ) in methanol and were stored at $-40{ }^{\circ} \mathrm{C}$. Working standard solutions were freshly obtained by diluting the stock solutions in water/acetonitrile/methanol $(2: 1: 1, \mathrm{v} / \mathrm{v} / \mathrm{v})$ containing $0.1 \%$ formic acid. The solutions were prepared under low light exposure and were filtered through a polyvinylidene fluoride (PVDF) syringe filter 
(13 mm diameter, $0.22 \mu \mathrm{m}$ pore size; Millipore Millex, Billerica, MA, USA) prior to injection.

\section{Sample preparation}

Ten tablets of the fixed-dose combination were crushed and an aliquot (equivalent to $25 \mathrm{mg}$ of ARS and $50 \mathrm{mg}$ of MFQ) was accurately weighed and transferred to a tube. Methanol $(10 \mathrm{~mL})$ was added to the tube and the samples were subjected to sonication for $5 \mathrm{~min}$ and subsequent centrifugation at $2,057 \times \mathrm{g}$ for $5 \mathrm{~min}$. The supernatant was transferred to a $25 \mathrm{~mL}$ volumetric flask and this process was further repeated. The samples were spiked with the IS and the final volume was reached with methanol. One aliquot of $1 \mathrm{~mL}$ was diluted in water/acetonitrile/ methanol $(2: 1: 1, \mathrm{v} / \mathrm{v} / \mathrm{v})$ containing $0.1 \%$ formic acid to obtain the following final concentrations: $100 \mathrm{ng} \mathrm{mL}^{-1}$ (IS), $500 \mathrm{ng} \mathrm{mL}^{-1}$ (ARS), and $1000 \mathrm{ng} \mathrm{mL}^{-1}$ (MFQ). The samples were prepared under low light and filtered through a PVDF syringe filter ( $13 \mathrm{~mm}$ in diameter, $0.22 \mu \mathrm{m}$ pore size; Millipore Millex, Billerica, MA, USA) prior to injection.

\section{LC-MS/MS analysis}

LC-MS/MS analyses were carried out in an Agilent 1200 HPLC Series (Agilent Technologies, Santa Clara, CA, USA), with a binary pump (G1312B), degasser (G1379B), thermostated column oven (G1316B), and CTC Sample Manager (Model 2777, Waters, Milford, MA, USA). The mass spectrometer coupled to the LC system was a triple quadrupole API 3200 system from Applied Biosystems MDS Sciex Instruments (Foster City, CA, USA) and was equipped with a syringe pump (Harvard Apparatus, Holliston, MA, USA). Chromatographic separation was performed on an XBridge C18 column $(50 \times 2.1 \mathrm{~mm}, 5 \mu \mathrm{m}$, Waters, Milford, MA, USA) coupled with an XBridge C18 guard column $(10 \times 2.1 \mathrm{~mm}, 5 \mu \mathrm{m}$, Waters, Milford, MA,
USA), maintained at $25{ }^{\circ} \mathrm{C}$. The mobile phase consisted of water/acetonitrile/methanol (30:35:35, v/v/v) containing $0.1 \%$ formic acid. The isocratic flow rate was $350 \mu \mathrm{L} \mathrm{min}^{-1}$, and the injection volume was $5 \mu \mathrm{L}$. The needle was washed with $2 \mathrm{~mL}$ of acetonitrile/methanol $(1: 1, \mathrm{v} / \mathrm{v})$ between each injection. The electrospray ionization (ESI) ion source was operated in positive ion mode with the following ion-source parameters: ion spray voltage, $5500 \mathrm{~V}$; source temperature, $400{ }^{\circ} \mathrm{C}$; nebulizer and auxiliary gas (nitrogen), $40 \mathrm{psi}$; collision activated dissociation gas (CAD), $10 \mathrm{psi}$; curtain gas (CUR), 10 psi. All analytes were evaluated in multiple reaction monitoring (MRM) mode, with a dwell time of $350 \mathrm{~ms}$. Ion transitions and individual analytes parameters including the declustering potential (DP), entrance potential (EP), collision cell entrance potential (CEP), collision energy (CE), and cell exit potential (CXP) are shown in Table 1.

The high-purity nitrogen and zero-grade air used as the CUR, GS1 (nebulizer gas), GS2 (turbo gas), and CAD gases were produced using a high-purity nitrogen generator from PEAK Scientific (Chicago, IL, EUA). Data acquisition was performed with an MS Workstation using Analyst 1.4 software (MDS Sciex, Concord, Ontario, Canada).

\section{Methodology parameters}

Validation was performed in accordance with the analytical method validation guidelines of the Agência Nacional de Vigilância Sanitária (ANVISA) and the International Conference on Harmonization (ICH). ${ }^{19,20}$ Selectivity was evaluated by comparing the chromatograms of each analyte for the appearance of co-eluting peaks with the same selected transition and retention times. Additionally, selectivity was evaluated by comparing the slopes of two analytical curves. An analytical curve obtained with the standard solution was compared with another analytical curve obtained with the diluted samples spiked with the

Table 1. Summary of the monitored ions and the MS/MS operating conditions for artesunate, mefloquine, and the internal standard indometacin

\begin{tabular}{|c|c|c|c|c|c|c|}
\hline & \multicolumn{6}{|c|}{ Precursor ions $(\mathrm{m} / \mathrm{z})$} \\
\hline & \multicolumn{2}{|c|}{ Artesunate $407.0[\mathrm{M}+\mathrm{Na}]^{+}$} & \multirow{2}{*}{\multicolumn{2}{|c|}{$\begin{array}{c}\text { Mefloquine } 378.9[\mathrm{M}+\mathrm{H}]^{+} \\
\text {Fragment ions }(\mathrm{m} / \mathrm{z})\end{array}$}} & \multicolumn{2}{|c|}{ Indometacin $357.9[\mathrm{M}+\mathrm{H}]$} \\
\hline & \multicolumn{4}{|c|}{ Fragment ions $(m / z)$} & & \\
\hline & $261.1^{\mathrm{a}}$ & $407.0^{\mathrm{b}}$ & $321.1^{\mathrm{a}}$ & $271.1^{\mathrm{b}}$ & $139.1^{\mathrm{a}}$ & $111.1^{\mathrm{b}}$ \\
\hline $\mathrm{CE} / \mathrm{eV}$ & 21.0 & 5.0 & 39.0 & 47.0 & 37.0 & 67.0 \\
\hline $\mathrm{CXP} / \mathrm{V}$ & 6.0 & 6.0 & 24.0 & 6.0 & 4.0 & 4.0 \\
\hline $\mathrm{CEP} / \mathrm{V}$ & 20.0 & 20.0 & 26.0 & 26.0 & 34.0 & 24.0 \\
\hline $\mathrm{DP} / \mathrm{V}$ & 36.0 & 36.0 & 51.0 & 51.0 & 36.0 & 36.0 \\
\hline $\mathrm{EP} / \mathrm{V}$ & 4.5 & 4.5 & 8.5 & 8.5 & 6.0 & 6.0 \\
\hline
\end{tabular}

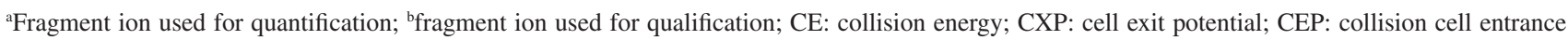
potential; DP: declustering potential; EP: entrance potential. 
analytes, at the same concentrations used to prepare the first curve. These curves were prepared in triplicate at concentrations of 400, 450,500, 550, and $600 \mathrm{ng} \mathrm{mL}^{-1}$ (ARS), and 800, 900, 1000, 1100, and $1200 \mathrm{ng} \mathrm{mL}^{-1}$ (MFQ), in the presence of $100 \mathrm{ng} \mathrm{mL}^{-1}$ (IS). The data was analyzed with linear regression analysis and an analytical curve was obtained. The slopes obtained from both analytical curves were compared and analyzed using the Student's $t$-test.

The matrix effect was evaluated by comparing the areas of the analytes obtained with spiked samples. The spiked samples with standard solutions were prepared as described in the selectivity study, in triplicate. The results of the comparison of the mean peak areas were expressed as percentages. Variations from 95 to $105 \%$ indicate the absence of a matrix effect. Accuracy was measured in triplicate using a recovery test. One sample was prepared at $50 \%$ of the target analyte concentration present in the tablet formulation as described in the Sample preparation section, and analyzed. The same sample was spiked with the standard solutions to obtain a concentration of 80, 100, and $120 \%$ of the target analyte concentration. The amounts of analytes recovered were calculated by subtracting the values of the analytes observed in the spiked samples from those obtained in the samples without standard addition. The percentage of recovery was calculated from the slope and the Y-intercept of the calibration curve.

Calibration curves were generated in triplicate at five different concentrations ranging from 80 to $120 \%$ of the target analyte concentration (ranges of $400-600 \mathrm{ng} \mathrm{mL}^{-1}$ for ARS, 800-1200 $\mathrm{ng} \mathrm{mL}^{-1}$ for MFQ, and all concentrations contained $100 \mathrm{ng} \mathrm{mL}^{-1}$ IS). For each compound, a calibration curve was generated to confirm the linear relationship between the analyte peak areas/IS peak areas and the analyte concentration/IS concentration. The slope, intercept, and coefficient of determination $\left(\mathrm{r}^{2}\right)$ were calculated as regression parameters by weighted $(1 / \mathrm{x})$ linear regression.

The repeatability and intermediate precision were determined by analyzing six samples at the target analyte concentration on two different days and the samples were prepared as described in the Sample preparation section. The repeatability measurements were conducted by the same researcher over a short period of time. The intermediate precision was determined by a second researcher, after two days. The results have been expressed as the relative standard deviation (RSD), and a Student's $t$-test was performed to compare the results of the analytes in each assay.

Stability studies for ARS and MFQ included bench-top stability (at $25^{\circ} \mathrm{C}$ for $6 \mathrm{~h}$ ), and long-term stability $\left(-40^{\circ} \mathrm{C}\right.$ for 30 days) determination for the standard stock solutions; sample and standard solution stabilities were tested in the
Sample Manager $\left(8^{\circ} \mathrm{C}\right.$ for $\left.24 \mathrm{~h}\right)$. The Student's $t$-test was performed to compare the results of freshly prepared sample and standard solutions with those obtained after storage at different conditions.

\section{Results and Discussion}

\section{Method development}

Analyte ionization was optimized by direct infusion of working standard solutions. The signal intensity was evaluated for each analyte by comparing the use of different mixtures of organic modifiers (acetonitrile, methanol, and water) containing different concentrations of additives (acetic acid, formic acid, and/or ammonium formate) for ion generation. Adequate signal intensity was observed for all compounds when acetonitrile/water plus $0.1 \%$ acetic acid and $5 \mathrm{mmol} \mathrm{L}^{-1}$ ammonium formate was used. In the case of MFQ and IS, the generation of $[\mathrm{M}+\mathrm{H}]^{+}$ ions was observed, while in the case of ARS, $\left[\mathrm{M}+\mathrm{NH}_{4}\right]^{+}$, adduct ions were generated. This result was in accordance with what published in the literature indicating the use of ammonium adduct to quantify ARS. ${ }^{21-23}$ However, during chromatographic optimization, no signal corresponding to the ARS $\left[\mathrm{M}+\mathrm{NH}_{4}\right]^{+}$adduct ion was observed. According to Grimalt et al..24 sodium adducts are more stable than ammonium adducts, owing to the strong interaction with the oxygen atoms present in the molecule. Hence, the generation of ARS $[\mathrm{M}+\mathrm{Na}]^{+}$adduct ion was evaluated. The compositions of organic modifiers and additives were adjusted for better ionization and good signal stability. The results obtained for the ARS sodium adduct were satisfactory, the strongest signal intensity for all of the compounds was produced by a mixture of methanol/ acetonitrile/water $(2: 1: 1, \mathrm{v} / \mathrm{v} / \mathrm{v})$ containing $0.1 \%$ formic acid. The methanol utilized as the organic modifier and present in the mobile phase contained traces of sodium that led to the formation of ARS sodium adduct ions.

Mass spectrometric parameters such as DP, EP, CEP, $\mathrm{CE}$, and CXP were optimized for each analyte in positive ionization mode with automatic multiple reaction monitoring (MRM) and the two most intense fragments were selected. An exception to this was ARS, for which the precursor ion and one fragment ion were monitored because the fragments showed low signal intensity after MS/MS optimization (Table 1). Source parameters (CUR, CAD, ISV (ion spray voltage), GS1, GS2, and temperature) were optimized by flowinjection analysis (FIA), which coupled LC with MS/MS. The pump was operated at $200 \mu \mathrm{L} \mathrm{min}{ }^{-1}$ using an isocratic system with a mobile phase consisting of water/acetonitrile/ methanol $(2: 1: 1, \mathrm{v} / \mathrm{v} / \mathrm{v})$ containing $0.1 \%$ formic acid. 
To identify the optimum chromatographic conditions, mobile phases with several combinations of acetonitrile, methanol, and water were tested. The initial experiments were conducted using a $\mathrm{C} 18$ column maintained at $25^{\circ} \mathrm{C}$, flow rate of $200 \mu \mathrm{L} \mathrm{min}{ }^{-1}$, and an injection volume of $10 \mu \mathrm{L}$. With a mobile phase consisting of water/acetonitrile/ methanol $(2: 1: 1, \mathrm{v} / \mathrm{v} / \mathrm{v})$ containing $0.1 \%$ formic acid, an extensive run time analysis was observed (> $15 \mathrm{~min}$ for ARS). Thus, several proportions of organic modifier were evaluated to achieve a shorter run time. In addition, the variations in the flow rate (range of $200-400 \mu \mathrm{L} \mathrm{mL}^{-1}$ ) and column oven temperature (range of $25-35^{\circ} \mathrm{C}$ ) were investigated. The injection volume of the sample was adjusted to $5 \mu \mathrm{L}$ for improvement of the chromatographic method. These results showed that the use of an isocratic mobile phase consisting of water/acetonitrile/methanol (30:35:35, v/v/v) containing $0.1 \%$ formic acid, eluted at $350 \mu \mathrm{L} \mathrm{min}{ }^{-1}$, at a column oven temperature of $25^{\circ} \mathrm{C}$, resulted in favorable peak shapes and shorter run time. Each chromatographic run was completed within $2 \mathrm{~min}$. This method showed advantages over other previously published methods where the run time was $13 \mathrm{~min}$, which is too long for the quantification of only two analytes. ${ }^{15}$ Furthermore, LC-MS/MS is not affected by the absence of good chromophore groups, which is the case for ARS. A representative chromatogram of the LC-MS/MS method is presented in Figure 2.

\section{Method validation}

Analytical figures of merit were assessed in order to evaluate the methodology developed here. For selectivity, as shown in Table 2, the slope comparison

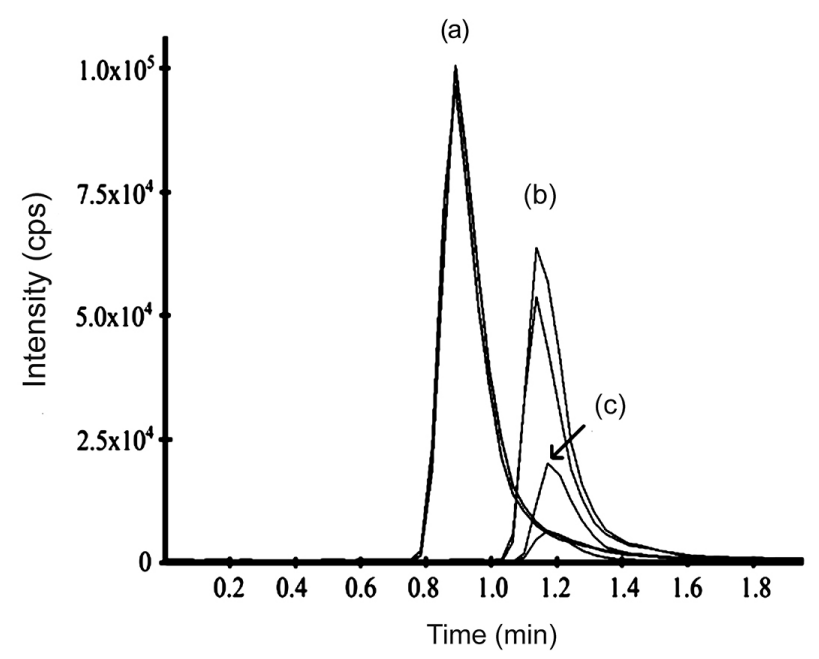

Figure 2. LC-MS/MS chromatogram of (a) artesunate at $500 \mathrm{ng} \mathrm{mL}^{-1}$ $(\mathrm{m} / \mathrm{z}, 407.0>261.1)$; (b) mefloquine at $1000 \mathrm{ng} \mathrm{mL}^{-1}(\mathrm{~m} / z .321 .1>271.1)$; and (c) internal standard indometacin at $100 \mathrm{ng} \mathrm{mL}^{-1}(\mathrm{~m} / \mathrm{z} 139.1>111.1)$.

of both curves (standard solutions and spiked samples) showed no significant variation for all compounds (RSD $<5 \%$; Student's $t$-test, $p>0.05$ ). Besides, no additional interferences were observed at the same retention time of the analytes of interest. Therefore, the selectivity of the developed method was found to be satisfactory. The matrix effect and accuracy data are shown in Table 3 . The present method showed that there was no matrix effect when the results of the concentration levels were compared (95 to $105 \%)$. In order to determine accuracy, satisfactory values ranging from 95.9 to $104.9 \%$ were obtained for ARS and MFQ at all the concentrations tested. The calibration curves for ARS and MFQ were evaluated and both showed good linearity with a coefficient of determination $\left(\mathrm{r}^{2}\right)>0.99$. The individual linear equations and correlation coefficients

Table 2. Statistical comparison of the slopes of the analytical curves for the determination of selectivity

\begin{tabular}{|c|c|c|c|c|c|c|}
\hline Compound & Curve & Slope & Average \pm SD & Variance & $\mathrm{RSD} / \%$ & $p$-value ${ }^{\mathrm{a}}$ \\
\hline \multirow{6}{*}{ Artesunate } & & 0.6594 & & & \multirow{6}{*}{2.65} & \multirow{6}{*}{0.676} \\
\hline & standard & 0.6524 & $0.6570 \pm 0.0041$ & $1.70 \mathrm{e}^{-05}$ & & \\
\hline & & 0.6597 & & & & \\
\hline & \multirow{3}{*}{ spiked sample } & 0.6327 & \multirow{3}{*}{$0.6500 \pm 0.0263$} & \multirow{3}{*}{$6.91 \mathrm{e}^{-04}$} & & \\
\hline & & 0.6365 & & & & \\
\hline & & 0.6800 & & & & \\
\hline \multirow{6}{*}{ Mefloquine } & & 0.5321 & & & \multirow{6}{*}{4.49} & \multirow{6}{*}{0.647} \\
\hline & standard & 0.5215 & $0.5230 \pm 0.0089$ & $7.90 \mathrm{e}^{-05}$ & & \\
\hline & & 0.5144 & & & & \\
\hline & \multirow{3}{*}{ spiked sample } & 0.4920 & & & & \\
\hline & & 0.4930 & $0.5120 \pm 0.0346$ & $1.20 \mathrm{e}^{-03}$ & & \\
\hline & & 0.5524 & & & & \\
\hline
\end{tabular}

a Student's $t$-test at 95\% confidence level. SD: standard deviation; RSD: relative standard deviation. 
Table 3. Matrix effect and accuracy of artesunate and mefloquine

\begin{tabular}{|c|c|c|c|c|c|c|c|}
\hline \multirow{2}{*}{ Compound } & \multicolumn{4}{|c|}{ Matrix effect / \% } & \multicolumn{3}{|c|}{ Accuracy } \\
\hline & Content / $\left(\mathrm{ng} \mathrm{mL}^{-1}\right)$ & Sample 1 & Sample 2 & Sample 3 & Level & Content / $\left(\mathrm{ng} \mathrm{mL}^{-1}\right)$ & Recovery $\pm \mathrm{SD} / \%$ \\
\hline \multirow{5}{*}{ Artesunate } & 400 & 104.72 & 102.62 & 104.65 & \multirow{2}{*}{ Low } & \multirow{2}{*}{400} & \multirow{2}{*}{$102.06 \pm 1.91$} \\
\hline & 450 & 100.28 & 103.88 & 101.14 & & & \\
\hline & 500 & 99.41 & 102.95 & 104.03 & Medium & 500 & $102.44 \pm 0.77$ \\
\hline & 550 & 101.30 & 99.93 & 104.31 & \multirow{2}{*}{ High } & \multirow{2}{*}{600} & \multirow{2}{*}{$103.43 \pm 0.60$} \\
\hline & 600 & 100.99 & 101.80 & 102.88 & & & \\
\hline \multirow{5}{*}{ Mefloquine } & 800 & 98.27 & 99.01 & 97.63 & \multirow{2}{*}{ Low } & \multirow{2}{*}{800} & \multirow{2}{*}{$97.44 \pm 2.48$} \\
\hline & 900 & 94.52 & 97.78 & 95.30 & & & \\
\hline & 1000 & 95.81 & 98.94 & 98.55 & Medium & 1000 & $98.67 \pm 2.37$ \\
\hline & 1100 & 97.50 & 99.54 & 101.07 & \multirow{2}{*}{ High } & \multirow{2}{*}{1200} & \multirow{2}{*}{$101.59 \pm 1.13$} \\
\hline & 1200 & 96.43 & 96.96 & 99.22 & & & \\
\hline
\end{tabular}

were as follows: ARS, $y=0.6594 x-0.1889\left(r^{2}=0.9939\right)$; MFQ, $y=0.5039 x-0.0978\left(r^{2}=0.9974\right)$. Additionally, the variations in precision and accuracy at all of the concentrations tested were below $5 \%$ for both analytes.

The repeatability and intermediate precision are presented in Table 4 . Both of the analytes RSD were $<2 \%$ and the comparison of the mean was statistically equivalent (Student's $t$-test, $p>0.05$ ), highlighting the precision of the method.

The stability tests were designed to take into consideration the anticipated conditions of handling real samples..$^{25}$ The recovery results of ARS and MFQ standard stock solutions were, respectively, 98.5 and $99.8 \%$ for long-term stability $\left(-40{ }^{\circ} \mathrm{C}\right.$ for 30 days), and 97.7 and $96.9 \%$ for bench-top stability (at $25^{\circ} \mathrm{C}$ for $6 \mathrm{~h}$ ). Analytical samples and standards stored in the sample manager $\left(8^{\circ} \mathrm{C}\right.$ for $24 \mathrm{~h}$ ) showed recoveries of 98.1 and $98.8 \%$ for ARS and 98.1 and $100.5 \%$ for MFQ, respectively. Under the tested conditions, the results were not statistically different from the results of freshly prepared standard solutions $(p>0.05$, Student's $t$-test, 95\% confidence level).

\section{Sample analyses}

The new method was successfully applied to determine ARS and MFQ in commercial samples containing $100 \mathrm{mg}$ of ARS and $220 \mathrm{mg}$ of MFQ (corresponding to $200 \mathrm{mg}$ of MFQ base). The composition obtained with the newly described method, for the commercial tablets were $98.71 \pm 4.72 \mathrm{mg}$ for ARS and $211.20 \pm 6.27 \mathrm{mg}$ for MFQ

Table 4. Repeatability and intermediate precision for artesunate and mefloquine

\begin{tabular}{|c|c|c|c|c|c|c|c|c|}
\hline \multirow{3}{*}{ Compound } & \multirow{3}{*}{ Sample } & \multicolumn{7}{|c|}{ Precision } \\
\hline & & \multicolumn{3}{|c|}{ Repeatability } & \multicolumn{3}{|c|}{ Intermediate precision } & \multirow[b]{2}{*}{$p^{\mathrm{a}}$} \\
\hline & & Assay / \% & Average \pm SD & $\operatorname{RSD}(n=6) / \%$ & Assay / \% & Average \pm SD & $\operatorname{RSD}(\mathrm{n}=12) / \%$ & \\
\hline \multirow{6}{*}{ Artesunate } & 1 & 96.38 & \multirow{6}{*}{$96.01 \pm 1.84$} & \multirow{6}{*}{1.91} & 98.68 & \multirow{6}{*}{$97.97 \pm 1.62$} & \multirow{6}{*}{2.00} & \multirow{6}{*}{0.156} \\
\hline & 2 & 93.93 & & & 97.23 & & & \\
\hline & 3 & 96.08 & & & 98.53 & & & \\
\hline & 4 & 99.31 & & & 96.79 & & & \\
\hline & 5 & 94.96 & & & 100.54 & & & \\
\hline & 6 & 95.38 & & & 96.02 & & & \\
\hline \multirow{6}{*}{ Mefloquine } & 1 & 101.36 & \multirow{6}{*}{$100.29 \pm 1.83$} & \multirow{6}{*}{1.82} & 98.06 & \multirow{6}{*}{$99.31 \pm 1.97$} & \multirow{6}{*}{1.89} & \multirow{6}{*}{0.695} \\
\hline & 2 & 97.08 & & & 96.46 & & & \\
\hline & 3 & 99.31 & & & 102.24 & & & \\
\hline & 4 & 102.17 & & & 100.21 & & & \\
\hline & 5 & 100.88 & & & 99.80 & & & \\
\hline & 6 & 100.95 & & & 99.10 & & & \\
\hline
\end{tabular}

aStudent's $t$-test, 95\% confidence level. SD: standard deviation; RSD: relative standard deviation. 
base, corresponding to 98.7 and $105.6 \%$ of the declared content per tablet. The tablet content was in accordance with the Brazilian Pharmacopoeia. ${ }^{12}$

\section{Conclusions}

A rapid and sensitive LC-MS/MS method was developed for simultaneous quantitative determination of ARS and MFQ in fixed-dose tablets. The results of the validation study suggest that the LC-MS/MS method was selective, linear, precise, and accurate. Analysis of real samples demonstrated the applicability of the new method. Based on these results, the new LC-MS/MS method could significantly contribute to the quality control of pharmaceutical preparations containing these drugs and could be easily applied to routine analyses.

\section{Acknowledgments}

The authors thank CAPES for fellowships, and the Fundação Oswaldo Cruz for providing the raw material of ARS, MFQ, and ARS-MFQ fixed-dose combination tablets.

\section{References}

1. Shapiro, T. A.; Goldberg, D. D. In Goodman and Gilman's The Pharmacological Basis of Therapeutics, $11^{\text {th }}$ ed.; Brunton, L. L.; Lazo, J. S.; Parker, K. L., eds.; McGraw-Hill: New York, 2006, p. 1021.

2. World Health Organization (WHO); World Malaria Report 2015; WHO: Geneva, Switzerland, 2015.

3. World Health Organization (WHO); Guidelines for the Treatment of Malaria; WHO: Geneva, Switzerland, 2015.

4. Varotti, F. P.; Botelho, A. C. C.; Andrade, A. A.; de Paula, R. C.; Fagundes, E. M. S.; Valverde, A.; Mayer, L. M. U.; Mendonça, J. S.; Souza, M. V. N.; Boechat, N.; Krettli, A. U.; Antimicrob. Agents Chemother. 2008, 52, 3868.

5. Wilairatana, P.; Krudsood, S.; Treeprasertsuk, S.; Chalermrut, K.; Looareesuwan, S.; Arch. Med. Res. 2002, 33, 416.

6. White, N. J.; Olliaro, P. L.; Parasitol. Today 1996, 12 (10), 399.

7. Newton, P. N.; Green, M. D.; Fernández, F. M.; Day, N. P. J.; White, N. J.; Lancet Infect. Dis. 2006, 6, 602.

8. César, I. C.; Nogueira, F. H. A.; Pianetti, G. A.; J. Pharm. Biomed. Anal. 2008, 48, 951.
9. World Health Organization (WHO); The International Pharmacopoeia, $5^{\text {th }}$ ed.; WHO: Geneva, Switzerland, 2015.

10. European Pharmacopoeia, $6^{\text {th }}$ ed.; Council of Europe: Strasbourg, 2008.

11. The United States Pharmacopeia, USP 36; The United States Pharmacopeial Convention: Rockville, 2013.

12. Agência Nacional de Vigilância Sanitária (ANVISA); Farmacopéia Brasileira, 5ª ed.; Brasília, 2010.

13. Kalyankar, T. M.; Kakade, R. B.; Attar, M. S.; Kamble, A. R.; J. Chem. 2013, 2013, 1.

14. Sourabh, K.; Ajay, G.; Mukut, T.; Surendra, S. I.; Rajesh, R; Int. J. Pharm. Res. Biosci. 2014, 3, 200.

15. Nogueira, F. H. A.; Reis, N. F. A.; Chellini, P. R.; César, I. C.; Pianetti, G. A.; Braz. J. Pharm. Sci. 2013, 49, 837.

16. Sandhya, S. M.; Shiji Kumar, P. S.; Meena, S.; Am. Chem. Sci. J. 2015, 7, 26.

17. Manikandan, K.; Lakshmi, K. S.; Geetha, Y.; Sowmiya, K.; Saranya, K.; J. Chem. Pharm. Sci. 2013, 6, 155.

18. ASTM E1657-98; Standard Practice for Testing Variable Wavelength Photometric Detectors Used in Liquid Chromatography; ASTM International: West Conshohocken, 2011.

19. Agência Nacional de Vigilância Sanitária (ANVISA); Guia para Validação de Métodos Analíticos e Bioanalíticos, Resolução RE No. 899 de 29 de maio de 2003, Brasília, 2003.

20. ICH, International Conference on Harmonization of Technical Requirements for Registration of Pharmaceuticals for Human Use, Q2B(R1), Validation of Analytical Procedurs: Text and Methodology; ICH: Geneve, 2005.

21. Hodel, E. M.; Zanolaru, B.; Mercier, T.; Biollaz, J.; Keiser, J.; Olliaro, P.; Genton, B.; Decosterd, L. A.; J. Chromatogr. B 2009, 877, 867.

22. Lindegardh, N.; Hanpithakpong, W.; Kamanikom, B.; Pattayaso, J.; White, N. J.; Day, N. P. J.; Bioanalysis 2011, 3, 1613.

23. He, G.; Qi, H.; Wang, M.; Yang, J.; Wen, F.; Wang, W.; Qiao, C.; Zhang, H.; J. Pharm. Biomed. Anal. 2013, 83, 186.

24. Grimalt, S.; Pozo, O. J.; Marin, J. M.; Sancho, J. V.; Hernandez, F.; J. Am. Soc. Mass Spectrom. 2005, 16, 1619.

25. Heaton, J.; Gray, N.; Cowan, D. A.; Plumb, R. S.; LegidoQuigley, C.; Smith, N. W.; J. Chromatogr. A 2012, 1228, 329.

Submitted: May 5, 2016

Published online: July 13, 2016 